\title{
Capital budgeting PRACTICES USED by SELECTED LISTED SouTh AFriCAN FIRMS
}

\author{
John Hall \\ Department of Financial Management, University of Pretoria \\ Sollie Millard \\ Department of Statistics, University of Pretoria \\ Accepted February 2009
}

\begin{abstract}
This article investigates the application of capital budgeting techniques and the incorporation of risk into the capital budgeting process among a sample of South African industrial firms listed on the JSE Securities Exchange for at least ten years. Previous international and local research on this topic indicated a preference for the internal rate of return (IRR) as a capital budgeting method over the net present value (NPV), and that risk incorporation was relatively rarely incorporated into the capital budgeting process. The results of this study indicate that the NPV is just as popular as, and sometimes more so than, the IRR. Furthermore, compared to previous studies, risk is incorporated into evaluating capital budgeting projects more often. Sensitivity analysis is the most popular method, but adjustments to the cash flows and discount rate are becoming more popular. During the last decade the use of non-financial criteria to accept or reject a project has also increased in South Africa.
\end{abstract}

Key words: Capital budgeting practices; net present value; internal rate of return; risk in capital budgeting; sensitivity analysis in capital budgeting

JEL G31

\section{1}

\section{Introduction}

The importance of capital budgeting for capital formation and the growth of a country's gross domestic product is undoubtedly one of the most important topics in economics today. Capital budgeting is not only a popular corporate finance topic, but it is also amongst the topics most widely researched by academics.

A capital budgeting project is a decision to make a cash outlay in order to receive future cash inflows. If the present value of the cash inflows exceeds that of the outlay, shareholder value is created. A number of stages, calculations, evaluation methods and refinements to the capital budgeting process can be used. It is these aspects of the capital budgeting process that are investigated in this study. The importance of the capital budgeting process for the firm lies in the fact that relatively large amounts of money are committed for a long time. Once the decision to start a project has been made, the process cannot be reversed unless a value destruction decision is taken to salvage what has been invested.

The purpose of this paper is to present evidence on capital budgeting practices based on a survey of a number of carefully selected companies listed on the JSE Securities Exchange (JSE). The first objective of this study was to investigate the capital budgeting techniques applied by the respondents. The second objective was to investigate the incorporation of risk in the capital budgeting process. This paper adds to a large collection of papers and research material on this topic, but it differs in a number of ways from previous surveys, especially from those on South African data. Firstly, the 
sample used in this survey is not a broad-based one, but it was chosen specifically to target a particular type of listed company. Secondly, the questionnaires were completed by means of personal interviews. Whilst this method has some disadvantages, it also has a number of advantages, such as a high response rate.

This paper specifically evaluates the following hypotheses in order to address the stated objectives:

Hypothesis 1:

The stages in the capital budgeting process were not all equally important.

Hypothesis 2:

The stages in the capital budgeting process were not all equally difficult.

Hypothesis 3

The listed cash flow forecasting methods were not all equally important.

Hypothesis 4

The listed capital budgeting techniques were not all equally important.

\section{Hypothesis 5}

The listed non-financial criteria used in major financial decisions were not all equally used.

Hypothesis 6

The listed risk stages were considered not to be equally risky.

\section{Hypothesis 7}

The listed risk analysis techniques were not all equally likely to be used.

Hypothesis 8:

The listed risk adjustment options were not all equally likely to be used.

The purpose of this paper was not to imitate or replicate previous studies, but to add to the body of knowledge by not only reporting on the findings with regard to this particular sample, but also comparing and contrasting its findings with those of other international and local studies in order to interpret any differences, if and wherever they are found.

The paper is organised as follows: in the next section, previous research on this topic is addressed; next, the research methodology is discussed, after which the empirical results are presented and evaluated; and, lastly, conclusions are drawn, recommendations are made and ideas for further research are presented.

2

\section{Previous research}

\subsection{South African studies}

Previous research on capital budgeting practices based on South African data includes that of Andrews and Butler (1986). They received 132 responses out of 500 companies and they found that larger firms tended to employ more sophisticated capital budgeting techniques. The uses of capital budgeting techniques in South Africa were also investigated by Hall (2000). In his studies, useable responses from 65 respondents out of a total population of 300 provided similar results to those of previous South African studies. A recent study by Du Toit and Pienaar (2005) also found that companies that undertake relatively large capital expenditures tend to prefer the IRR and the net present value (NPV) method. The latter study was based on 64 useable responses from a population of 524 .

There are a number of studies on risk incorporation in the capital budgeting decision by South African firms. Parry and Firer (1990) found that 18 per cent of their respondents had no response to any technique, but that 61 per cent sometimes or often used sensitivity analysis. Hall (2001) found that 25 per cent of the larger firms (and approximately 40 per cent of smaller firms) who responded to his survey at that time did not use any formal risk adjustment technique. In his study, sensitivity analysis was also found to be the most popular and it was used by 40 per cent of the larger firms that responded. However, sensitivity analysis can be regarded as a relatively unsophisticated risk adjustment tool, compared to techniques like decision trees, simulation (including Monte Carlo simulation) and real option analysis.

\subsection{International studies}

International studies over four decades on capital budgeting practices, show that there has been a definite shift in the capital budgeting 
evaluation techniques employed by companies. A study by Ryan and Ryan (2002) indicated that financial managers have never been in full agreement as to the choice of the best capital budgeting method. According to Ryan and Ryan (2002), earlier studies by Miller in 1960, by Schall, Sundam and Geijsbeek in 1978 and by Pike in 1996 reported the payback technique to be the preferred method and discounted cash flow models to be the least popular. This may be attributed to lack of financial sophistication (and even training or education in corporate finance) and the limited use of computer technology in that era. Ryan and Ryan (2002) reported more recently, that a decrease in the use of the accounting rate of return was found by Jog and Srivastava in Canada in 1995 and by Pike in the United Kingdom in 1996.

A very similar pattern can be noted in the capital budgeting practices of multinational firms. Kim and Ulferts (1996) summarised the results of five studies from 1980 to 1993 . The results of these five empirical studies revealed that discounted cash flow techniques were more popular than other techniques and that the IRR was the most popular capital budgeting technique. At least half of the respondents in all the studies they summarised used discounted cash flow techniques. In one study, 81 per cent of the respondents used either the NPV or the IRR. In a study on the same topic, following eight research projects from 1959 to 1981 Stanley and Block (1984) found that not only were the NPV and the IRR the most popular capital budgeting evaluation techniques for a multinational corporation, but also over time, these techniques had become more popular. It can be assumed that this trend will continue in future.

Graham and Harvey (2001) found that CEOs with MBAs are more likely to use the NPV method than those without MBAs, possibly because the NPV method is regarded as a more sophisticated capital budgeting method than some other methods.

A detailed analysis of a number of past studies on capital budgeting techniques by Cooper et al. (2002) confirmed the shift towards discounted cash flow techniques over time. In their analysis of various research projects, they found that as a primary capital budgeting method the IRR had increased in popularity from 10 per cent in 1959 to 41 per cent by 1975 and to 57 per cent by 1990 . However, the NPV did not enjoy either the same popularity or the same spectacular increase in use over time.

On the other hand, there were indications in a study by Kim and Farragher (1983) that, while most business executives understand the new analytical techniques and recognise the importance of these methods, there seems to be a time lag in the practical implementation of these methods. Recent surveys revealed an increased effort to use sophisticated risk analysis techniques for capital budgeting projects. These new techniques will probably be used increasingly as more standardised and sophisticated computer programs become readily available.

Parry and Firer (1990) reported that in a study by Petty et al. in 1975, a surprisingly high percentage of 77 per cent of firms used an adjustment of the payback period to adjust for risk. They also reported that 42 per cent of the respondents in a study by Buler in 1982 used this method to compensate for risk. Gitman and Forrester (1977) found that 71 per cent of their respondents gave explicit consideration to risk. They argued that these results were confirmed by a study by Fremgen in 1973 in which 67 per cent of Fremgen's respondents incorporated risk in the evaluation of their capital budgeting projects.

It seems therefore that empirical studies covering several decades, indicate that for a long time the NPV trailed the IRR as preferred capital budgeting method and the incorporation of risk in the capital budgeting process varies both in the methods applied as well as in the rate of application of these methods.

3

\section{Research method}

The way the sample of this study was constructed from the total population lies at the heart of this research project. The database of the Bureau of Financial Analysis (BFA) at the University of Pretoria was used to assist in the compilation of this sample. In order to select the sample of 
companies, a number of guidelines were set. Firstly, it was decided to use only industrial companies, as the nature of their activities complies best with the nature and objectives of this study. At the end of 2005, a total of 177 industrial companies was listed on the JSE Securities Exchange (JSE). Secondly, in order to obtain more meaningful results and to add more weight to the responses, only companies that had been listed for at least ten years were included in the sample. Thirdly, companies were also questioned on the discount rate used in the evaluation of the capital budgeting decision. Because the cost of equity can be calculated by means of the capital asset pricing model (CAPM), where the beta $(\beta)$ plays an important role in the actual calculation, companies whose shares traded less than 500000 shares per year were excluded from the sample, since the beta calculation might be distorted. This left 67 companies in the final sample. At each of these companies, one decision-maker was interviewed using a structured questionnaire.

Once the sample had been selected, the design of the questionnaire was undertaken. The questionnaire consisted of four sections. The first section dealt with the company and decision-maker profile, which was necessary to categorise the data of the various responses. It gave an indication of the seniority and level of education of each decision-maker surveyed. It also indicated the size of the company and its capital budget. Eight questions were asked in Section One of the questionnaire.

Section Two dealt with the stages of the capital budgeting process, as well as the various capital budgeting techniques employed for different types of projects by the various respondents. This section consisted of ten questions.

Section Three dealt with the incorporation of risk in the capital budgeting decision and consisted of five questions. The last section investigated the use and various aspects of a discount rate in the capital budgeting process. The results of this section will be discussed in a subsequent paper.

The statistical analysis includes a basic descriptive analysis as well as Chi Square tests for uniformity.
4

\section{Empirical analysis}

\subsection{Introduction}

The data was collected by means of personal interviews with the person responsible for the capital budgeting process at each of the identified companies. In the end, 41 usable responses were gleaned from the 67 sample companies, which were used in the empirical analysis.

\subsection{Company and decision-maker's profile}

The profile of the company and the company decision-maker provide some indication of the level of experience and education of the capital budgeting decision-maker in the firm, as well as the size of the firm. This information places in perspective the results of the actual capital budgeting processes and techniques that individual firms apply in practice.

The first question dealt with the job title of the respondent. In 50 per cent of the cases, the job title of the capital budgeting decision-maker was given as that of 'Financial Manager', and in 18 per cent of the cases it was 'Financial Director'.

The next three questions were designed to establish the level of education and expertise of the respondents. It was established that 68 per cent of the respondents had been employed by their companies for more than five years, while 18 per cent had been employed between two and five years. The balance had been employed for less than two years. Of the respondents, 40 per cent had been in their current positions for more than 5 years, 30 per cent have been in their current positions for between two and five years, and 30 per cent had been in these positions for less than two years. With regard to the academic qualifications of the respondents, it was determined that 65 per cent had a postgraduate qualification (an honours or master's degree), 16 per cent had a basic bachelor's degree, and 19 per cent had other qualifications (diplomas, certificates or other training). From these results one can deduce that the majority 
of the capital budgeting decision-makers had a good academic grounding and sufficient experience in their decision-making capacity with their firms.

There was a relatively even distribution of the 41 companies within the 15 applicable industrial sub-sectors of the JSE. No particular sub-sector dominated substantially, attracting more respondents than any other sub-sector. These results therefore support those on the capital budgeting practices. An even distribution of representation amongst various industries is preferable to a situation where responses from one or two sectors or industries dominate the overall responses.

Tables 1 and 2 illustrate the respondents' total assets, the amount of annual sales and the size of the annual capital budget. The results of the firms' sizes according to their total assets show that by far the majority of the respondents (73 per cent) had assets of more than R1 billion. A relatively even distribution amongst the other monetary ranges represented the balance.

Table 1

Amount of total assets

\begin{tabular}{|l|c|}
\hline \multicolumn{1}{|c|}{ Total assets } & $\%$ \\
\hline Less than R100 million & 7.3 \\
Between R100 million and R200 million & 9.8 \\
Between R200 million and R500 million & 2.4 \\
Between R500 million and R1 billion & 7.3 \\
More than R1 billion & 73.2 \\
\hline & 100 \\
\hline
\end{tabular}

A similar pattern can be found in Table 2, which suggests that more than 90 per cent of the firms in the sample have sales in excess of R200 million. An analysis of the results of the firms' annual capital budgets revealed two main categories. In the first place, 25 per cent of the respondents had a capital budget of less than R50 million. Secondly, and more importantly, 60 per cent of the respondents had an annual capital budget in excess of R200 million. The importance of the capital investment decision is clear, as one can extrapolate that if 60 per cent of 41 respondents spend more than R200 million, the total capital expenditure of this sample is more than R5 billion annually.

Table 2

Annual sales and size of annual capital budget

\begin{tabular}{|l|c|c|}
\hline \multicolumn{1}{|c|}{ Range } & $\begin{array}{c}\text { Annual sales } \\
\%\end{array}$ & $\begin{array}{c}\text { Annual capital } \\
\text { budget } \\
\%\end{array}$ \\
\hline Less than R50 million & 4.9 & 25.0 \\
Between R50 million and R100 million & 0.0 & 2.5 \\
Between R100 million and R150 million & 2.4 & 7.5 \\
Between R150 million and R200 million & 2.4 & 5.0 \\
More than R200 million & 90.3 & 60.0 \\
\hline
\end{tabular}


The results of the company and decision-maker profiles for this sample were to be expected, given the nature of the sample of companies for this study. Industrial companies listed for at least ten years created a sample that gave specific meaning and weight to the results of the importance of the stages in the capital budgeting process, as well as the capital budgeting techniques that these firms apply in practice.

\subsection{Stages in the capital budgeting process}

As one can see from Table 3, the majority of the respondents regarded project definition and cash flow estimation as the most important and the most difficult (p-values of 0.0008 and 0.0005 respectively). Financial analysis was regarded as the second most important, but not as difficult. This could stem from the fact that the respondents are well educated, with a relatively high level of work experience. Project implementation was regarded as the most difficult jointly with the cash flow estimation.

Table 3

Most important and most difficult stages in the capital budgeting process

\begin{tabular}{|l|c|c|}
\hline \multicolumn{1}{|c|}{ Stage } & $\begin{array}{c}\text { Most important } \\
\%\end{array}$ & $\begin{array}{c}\text { Most difficult } \\
\%\end{array}$ \\
\hline Project definition and cash flow estimation & 57.1 & 41.5 \\
Financial analysis and project selection & 33.3 & 9.8 \\
Project implementation & 9.6 & 41.5 \\
Project review & 0.00 & 7.2 \\
\hline & 100 & 100 \\
\hline p-value for uniformity & 0.0008 & 0.0005 \\
\hline
\end{tabular}

It was very interesting that in this analysis the respondents gave project review such a low rating. Project review and follow-up after implementation are now regarded as playing a much more important in the capital budgeting process than in the past. The last phase in an integrated capital budgeting system is post-auditing the project. It first involves the examination of the project's progress in its implementation phase, and second, an in-depth analysis of the actual costs and benefits to date, the likely future prospects of the project and a comparison of these prospects to the initial expectations. The core aims of a post-audit system are usually to improve capital budgeting decision-making, to assess management expertise in evaluating, implementing and operating a project, and to identify and correct discrepancies early in a project's life. Post-completion auditing is both part of the capital budgeting system and its regulator. If any deviations from the budget emerge during this process, investigators may suggest one of three possible actions: fine-tuning the project to get it back on course, a significant change in the future development of the project, or outright abandonment of the project. The adoption of the post-completion audit by companies over three decades was tabled by Neale (1994). These past surveys revealed clear but apparently shrinking disparities between US and UK companies over time. It seems, however, that on average US companies have a higher post-audit adoption rate (seldom below 80 per cent in seven surveys) than the UK companies (in the region of a 60 per cent adoption rate over seven surveys).

Capital budgeting post-audits play a potentially critical role in helping firms to learn from their past experiences and in providing a mechanism for transferring knowledge relevant to improving procedures and therefore more effective decision-making throughout an organisation. 


\subsection{Cash flow forecast method used}

The question which cash flow forecasting method the respondents used, provided the respondents with four alternatives, as set out in Table 4 below.

The results from this question are somewhat disturbing, since using management's subjective estimates was the most popular cash flow forecasting method having a p-value of less than 0.0001 . This method was chosen above formal quantitative measures, which was used in only 33.3 per cent of the cases. If management's subjective estimates are added to the responses of respondents who 'cannot say' what method they used, we find that 50 per cent of respondents appeared not to use a formal cash flow forecasting methods to estimate their future cash flows.

Table 4

Cash flow forecasting methods used

\begin{tabular}{|l|c|}
\hline \multicolumn{1}{|c|}{ Cash flow forecasting method } & $\%$ \\
\hline Management subjective estimate & 46.3 \\
Quantitative methods & 33.3 \\
Consensus of expert's opinions & 14.8 \\
Cannot say & 5.6 \\
\hline & 100 \\
p-value for uniformity & $<0.0001$ \\
\hline
\end{tabular}

\subsection{Capital budgeting techniques}

One of the most important questions that needs to be answered by any study on capital budgeting practices is what the respondents' preferences are regarding the most important capital budgeting technique to be used.

The results for this question are set out in Table 5 below. From the results it is clear that the null hypothesis can be rejected having a pvalue $=0.0004$. The statistical results indicated that return on investment (ROI) was the most popular method, with a third of the respondents choosing this method. The NPV was second, with nearly 29 per cent, and the IRR came third with nearly 24 per cent. The profitability index, present value payback and the accounting payback did not appear to play any significant role in the capital budgeting decision-making process, with the latter method receiving no responses at all.

Table 5

Preferences regarding the most important capital budgeting techniques

\begin{tabular}{|l|c|}
\hline \multicolumn{1}{|c|}{ Technique } & $\%$ \\
\hline Return on investment & 33.3 \\
Net present value & 28.6 \\
Internal rate of return & 23.7 \\
Profitability index & 4.8 \\
Present value payback & 4.8 \\
Accounting payback & 0.0 \\
Other & 4.8 \\
\hline & 100 \\
\hline
\end{tabular}


The fact that the ROI was selected as the most popular capital budgeting evaluation technique is in line with the results of previous research on South African companies by Hall (2000). The question arises, however, how exactly the respondents defined 'return on investment'. Both the 'return' and the 'investment' components of the term are subject to different interpretations and definitions. Nevertheless, the fact that it remains a popular method cannot be denied.

The findings of this study show that the preference for the NPV as a capital budgeting evaluation technique is not significantly ( $p$ value $=0.7165$ ) above the IRR and is in contrast with the findings of previous studies. As has already been mentioned above, research results from a number of South African and international studies indicated that the IRR is more popular than the NPV. Academics prefer the NPV above the IRR as a capital budgeting method, especially when they are evaluating mutually exclusive projects. The NPV has better re-investment rate assumptions and provides a more value-enhancing decision when there is a conflict in the ranking of projects between the NPV and the IRR.

In this study the preference of the NPV and IRR as capital budgeting techniques can possibly be attributed to the fact that the sample companies are large, well-established concerns with well-educated decision-makers.

With regard to the capital budgeting techniques used, respondents were asked whether they applied different techniques when they assessed different types of projects. Six different types of projects were identified, namely the expansion of existing projects, the expansion of new projects, foreign projects, the abandonment of projects, general or administrative projects and social projects. A summary of the various responses is given in Table 6 below.

\section{Table 6}

Techniques most often used in assessing different operations

\begin{tabular}{|c|c|c|c|c|c|c|c|}
\hline & $\begin{array}{c}\text { IRR } \\
\%\end{array}$ & $\begin{array}{l}\text { NPV } \\
\%\end{array}$ & $\begin{array}{l}\text { PI } \\
\%\end{array}$ & $\begin{array}{c}\text { PVP } \\
\%\end{array}$ & $\begin{array}{c}\text { APB } \\
\%\end{array}$ & $\begin{array}{c}\text { ROI } \\
\%\end{array}$ & $\begin{array}{c}\text { Other } \\
\%\end{array}$ \\
\hline $\begin{array}{l}\text { Capital investment projects } \\
\text { in general }\end{array}$ & 21.4 & 31.0 & 7.1 & 7.1 & 0 & 31 & 2.4 \\
\hline $\begin{array}{l}\text { Expansion of existing } \\
\text { projects }\end{array}$ & 18.5 & 27.9 & 7.0 & 7.0 & 0 & 32.6 & 7.0 \\
\hline Expansion in new projects & 15.8 & 29.6 & 9.1 & 4.6 & 2.3 & 31.8 & 6.8 \\
\hline Foreign projects & 15.5 & 18.8 & 3.1 & 6.3 & 0 & 43.8 & 12.5 \\
\hline Abandonment & 7.9 & 39.5 & 18.4 & 5.3 & 2.6 & 15.8 & 10.5 \\
\hline $\begin{array}{l}\text { General/administrative } \\
\text { projects }\end{array}$ & 7.5 & 25.0 & 2.5 & 15.0 & 15.0 & 20.0 & 15.0 \\
\hline Social projects & 5.4 & 8.1 & 2.7 & 8.1 & 8.1 & 8.1 & 59.5 \\
\hline
\end{tabular}

From these responses, a number of very definite trends emerge. ROI is still the most popular method for the first four more traditional capital budgeting operations (namely projects in general, expansion of existing and new projects and foreign projects). As a matter of fact, the popularity of the ROI reached a very high 44 per cent for foreign projects. After the ROI, the NPV was rated the second most popular method for evaluating these projects, even more than the IRR. This is in line with the findings set out in Table 5 above when the overall most important capital budgeting method was chosen, but contrasts with the results of previous studies, which cited the IRR as more popular than the NPV in most cases. When the abandonment of projects and administrative projects was evaluated, the NPV was the most popular method.

There seems therefore to be some correlation between the use of the ROI as a capital budgeting 
evaluation method when it comes to traditional, value-creating types of projects. The rise of the popularity of NPV as evaluation method to almost as popular as the ROI in these types of project is also noteworthy. In addition to this trend, the IRR seems to have lost some of its appeal amongst the respondents of this study in favour of the NPV as a capital budgeting method.

Table 7

Non-financial capital budgeting evaluation criteria

\begin{tabular}{|l|c|}
\hline \multicolumn{1}{|c|}{ Item } & $\%$ \\
\hline Legal requirements & 20.6 \\
Necessity of maintaining existing projects & 16.5 \\
Safety of employees or public & 16.5 \\
Social concern & 13.4 \\
Pollution control & 12.4 \\
Contractual commitments & 10.3 \\
Investments never accepted on non-financial grounds & 6.2 \\
Employee's convenience & 4.1 \\
\hline & 100 \\
p-value for uniformity & 0.0204 \\
\hline
\end{tabular}

Table 7 provides a summary of the non-financial criteria that can be applied when evaluating a capital budgeting project.

It is interesting to note that in only 6.2 per cent of the cases investments were never accepted on non-financial grounds ( $\mathrm{p}$-value 0.0204 ). This is in sharp contrast to a previous study by Hall (2000), where it was found that nearly 34 per cent of respondents never accepted investments on non-financial grounds. As one can see from the above table, legal requirements were the biggest non-financial factor when respondents evaluate capital budgeting projects. It can be argued that maintaining existing projects is often a case of 'in for a penny, in for a pound'. It is however still a situation where additional (unforeseen) outlays in an investment project may be undertaken without financial evaluation. It therefore seems that over time, especially amongst the respondents of the current study, there is a tendency for non-financial criteria to play a more important role in the evaluation of investment projects.

\subsection{The incorporation of risk in the capital budgeting process}

The importance of incorporating risk in the capital budgeting process has been preached by academics for years. As indicated above, a number of studies, both local and international, have been conducted in order to establish the use of risk adjustment techniques in capital budgeting by practitioners.

Table 8 gives an indication as to what the respondents regard as the highest risk stage in the capital budgeting process.

It seems that project definition, cash flow estimation and project implementation are considered to be of equal risk ( $\mathrm{p}$-value = 0.5836 ). This finding corresponds with what the respondents considered to be the most difficult stage in the capital budgeting process (see Table 3 above). 
Table 8

Highest risk stage in capital budgeting process

\begin{tabular}{|l|c|}
\hline \multicolumn{1}{|c|}{ Item } & $\begin{array}{c}\text { Highest risk } \\
\%\end{array}$ \\
\hline Project definition and cash flow estimation & 35.0 \\
Financial analysis and project selection & 25.0 \\
Project implementation & 37.5 \\
Project review* & 2.5 \\
\hline p-value for uniformity & 100 \\
*Excluded from test since only 1 respondent selected this item. & 0.5836 \\
\hline
\end{tabular}

This finding contrasts with previous conclusions by Hall (2000), who found that the project definition and cash flow estimation were considered to be significantly more risky (46.2 per cent) than any other stage. There therefore seems to be a marked increase in the risk consideration that especially the project implementation stage carries. The fact that the financial analysis was considered to be relatively less risky could stem from the fact that the respondents are academically well educated with a high level of experience and are therefore at ease with the actual financial calculations and analysis of the project.

Respondents were then asked to indicate the specific risk analysis technique that they used.
These results are summarised in Table 9 below. The statistical analysis indicates that the risk analysis techniques are not equally likely to be used, having a p-value $<0.0001$. From this table it is clear that only 7 per cent indicated that they used no formal technique. This is in sharp contrast to the results of previous studies where it was found that up to 40 per cent of respondents did not use any formal technique to incorporate risk in the capital budgeting process. The trend that more respondents actually do incorporate risk in their capital budgeting decision can be ascribed to a number of reasons, such as the compilation of the specific sample of this study, as well as the fact that we live in an increasingly uncertain world where more risk factors have to be incorporated in any financial decision.

Table 9

Risk analysis techniques

\begin{tabular}{|l|c|}
\hline \multicolumn{1}{|c|}{ Risk analysis technique } & $\%$ \\
\hline Sensitivity analysis & 29.2 \\
Adjusting required rate of return & 22.2 \\
Scenario analysis & 13.9 \\
Adjusting cash flows & 12.5 \\
No formal technique in use & 6.9 \\
Monte Carlo simulation & 4.2 \\
Sophisticated mathematical modelling (Option analysis) & 4.2 \\
Decision trees & 2.8 \\
Other & 4.1 \\
\hline & 100 \\
p-value for uniformity & $<0.0001$ \\
\hline
\end{tabular}


Sensitivity analysis was indicated as the most popular method to incorporate risk in the capital budgeting decision. Whether sensitivity analysis is an actual technique to quantify risk is debatable. Sensitivity analysis per se does not quantify risk, but it can be used by companies as a relatively simple and cost-effective way to determine the sensitivity of the NPV or IRR to changes in key input variables. In this way, it facilitates more prudent decision-making. Changing the discount rate or the cash flows in order to incorporate risk in the capital budgeting process was considered by many respondents to be a sufficient way of dealing with uncertainty in capital budgeting. A total of 35 per cent of the respondents used one of these methods. Option analysis was regarded as a relatively sophisticated way of dealing with risk, and it is disappointing that only 4 per cent of respondents reported using this method.

Lastly, respondents were asked to indicate adjustments to accommodate fluctuations in the inflation rate.

The survey responses are set out in Table 10 below.

Table 10

Adjustments to accommodate fluctuations in the inflation rate

\begin{tabular}{|l|c|}
\hline \multicolumn{1}{|c|}{ Item } & $\%$ \\
\hline No allowances are made for inflation & 16.7 \\
Use various inflation rates for different annual cash flows & 42.9 \\
Use a single inflation rate for different annual cash flows & 40.4 \\
\hline & 100 \\
p-value for uniformity & 0.0712 \\
\hline
\end{tabular}

From this table one can see that only 16.7 per cent of the respondents did not make any adjustments for inflation. In the previous study by Hall (2000), it was found that 23 per cent did not make any adjustments for inflation. Once again, there seems to be an improvement in the way the whole capital budgeting process is being conducted, although the results are not statistically significant with a p-value $=0.0712$. While South Africa is in a period of relatively high inflation, one would like to see the trend of more companies incorporating inflation in their analyses continuing.

\section{Conclusion}

The objectives of this study were to investigate the capital budgeting practices of listed South African industrial firms and to compare the results to those of other international and South African studies. In order to give weight and meaning to the results of this study, the sample of companies was carefully constructed to target large, well established listed firms.
The decision-maker profile of the respondents of this study indicates that nearly 70 per cent had been employed by their company for more than five years, and that more than 80 per cent had a bachelor's or post-graduate qualification. It therefore seems that the respondents are suitably qualified, both in terms of their academic training and their work experience, to make well-informed capital budgeting decisions and to apply prudent capital budgeting evaluation techniques.

The respondent companies were evenly distributed over the industrial sub-sectors of the JSE. Of the respondents' companies, 73 per cent had assets of more than R1 billion and 60 per cent had an annual capital budget of more than R200 million. The stage was set for very meaningful and interesting results.

Project definition and cash flow estimation were regarded as the most important and most difficult stages in the capital budgeting process. Financial analysis was considered to be important, but not difficult at all to the respondents - a clear indication of their level of 
education and work experience. However, what was disappointing was the fact that the majority relied on management subjective estimates as cash flow forecasting methods, as opposed to quantitative methods.

One of the most interesting results came from the capital budgeting techniques used by the respondents. As with previous studies, it was found that the ROI is the most popular method, with one third of the respondents using this method. A new trend that emerged from this study, however, was the fact that the NPV was considered to be more popular than the IRR. In the majority of previous studies, both local and international, the IRR was more popular than the NPV. Academics prefer the more theoretically and mathematically sound NPV to the IRR, and the fact that this was also the choice amongst the practitioners responding to this study may indicate a major shift in capital budgeting practices amongst the respondents of this study.

Non-financial criteria seem to play a more important role in the evaluation of capital budgeting projects than in the past. In this study, legal requirements accounted for nearly 21 per cent of the non-financial selection criteria, with only 6 per cent of respondents never selecting investments on non-financial criteria, as opposed to 34 per cent never considering non-financial factors in a previous study. This trend can possibly be ascribed to the fact that the South African economic, financial and social landscape is being increasingly stringently regulated by government.

Regarding the incorporation of risk in the capital budgeting process, it was found that the project implementation stage is considered to be the most risky. This is in contrast to a previous study, in which respondents considered the project definition and cash flow estimation to be riskier. This change can be ascribed to not only the relatively high experience of the respondents, but also to the ever-changing South African economic environment. As a matter of fact, the world has become an increasingly difficult place in which to conduct business at an acceptable level of risk. Whilst the majority of respondents used sensitivity analysis to account for risk in the capital budgeting process, 35 per cent of respondents used either changes in the cash flows or the discount rate to account for uncertainty. Lastly, it was noted that the trend is for more respondents than in previous studies to incorporate inflation in their capital budgeting process. This trend may be ascribed to the fact that more sophistication is introduced.

The fact that more respondents in this study than in previous ones prefer the NPV to the IRR, as well as the greater level of risk incorporation in the capital budgeting process, is an indication of the use of an improved capital budgeting selection process by the respondents of this study.

Further research on the capital budgeting process might include a more detailed exposition of the ROI and how respondents define this method. In addition, the use amongst practitioners of methods such as the modified internal rate of return (MIRR), as well as economic value added (EVA), in their capital budgeting process could provide interesting results.

\section{References}

ANDREWS, G.S. \& BUTLER, F. 1986. Criteria for major investment decisions. The Investment Analysts Journal, 27: 31-37.

COOPER, W.D., MORGAN, R.G., REDMAN, A. \& SMITH, M. 2002. Capital budgeting models: Theory vs. practice. Business Forum, 26(1): 15-19.

DU TOIT, M.J. \& PIENAAR, A. 2005. A review of capital budgeting behaviour of large South African firms. Meditari Accountancy Research, 13(1): 19-27. GITMAN, L.J. \& FORRESTER, J.R. 1977. A survey of capital budgeting techniques used by major U.S. firms. Financial Management, Fall: 66-71.

GRAHAM, J.R. \& HARVEY, C.R. 2001. The theory and practice of corporate finance: Evidence from the field. Journal of Financial Economics, 60: 187-243. HALL, J.H. 2000. Investigating aspects of the capital budgeting process used in the evaluation of investment projects. South African Journal of Economic and Management Sciences, 3(3): 353-368.

HALL, J.H. 2001. Risk analysis and evaluation of capital investment projects. South African Journal of Economic and Management Sciences. 4(2): 398-411. KIM, S.H. \& FARRAGHER, E.J. 1983. An empirical study on the relationship between capital budgeting practices and earnings performance. Engineering Economist, Spring: 26-30. 
NEALE, C.W. 1994. Investment post-auditing practices among British and Norwegian companies: A comparative study. International Business Review, 3 (1): 31-46.

PARRY, H.M.A. \& FIRER, C. 1990. Capital budgeting under uncertainty: an empirical study. South African Journal of Business Management, 21(3): 52-58.
RYAN, A.R. \& RYAN, G.P. 2002. Capital budgeting practices of the fortune 1000: How have things changed? Journal of Business and Management, 8(4): 355-364.

STANLEY, M.T. \& BLOCK, S.B. 1984. A survey of multinational capital budgeting, Financial Review, Spring: 36-54. 